\title{
CONTRAIMÁGENES INFILTRADAS. ESTRATEGIAS ARTÍSTICAS PARA LA CREACIÓN DE DISPOSITIVOS DE ACCIÓN POLÍTICA*
}

\section{INFILTRATED COUNTERIMAGES: ARTISTIC STRATEGIES FOR THE CREATION OF POLITICAL ACTION APPARATUSES}

\author{
RUT MARTÍNEZ HERNÁNDEZ**
}

RESUMEN: Este trabajo aborda la relación entre el arte, las imágenes mediáticas y el artivismo. La investigación analiza las posibilidades de dicho vínculo para la creación de contradiscursos visuales que vengan a cuestionar los relatos de los medios de comunicación y a plantear una serie de transformaciones de índole social y política. El objetivo general es investigar qué estrategias artísticas se han desarrollado en el campo del activismo artístico y cuáles son sus modos de operar en lo social y en lo mediático. Para ello, se establece una muestra de propuestas artísticas activistas seleccionadas en función de su impacto, pertinencia y actualidad, que permiten, a partir de su análisis, visualizar los nodos de conexión con las imágenes mediáticas y el activismo. Los resultados determinan una serie de estrategias comunes en las prácticas artivistas contemporáneas, estrategias que permiten cartografiar las transformaciones de las formas y modos de acción de dichas prácticas.

Palabras clave: Artivismo, imágenes, arte político, estrategias artísticas, medios de comunicación.

Aвstract: This article examines the relation between art, mass media and artivism through an analysis of how this interaction generates the potential for creating visual counterdiscourses that question media representations and propose a series of social and political transformations. The primary of objective of this work is to examine the artistic strategies developed in the field of artistic activism (artivism) and how these are employed in society and mass media. To this end, a selection of art-activist proposals is established in view of their impact, relevance and topicality in order to visualize the nodal points that connect media imagery and activism. The results of this study reveal

\footnotetext{
* Este trabajo se ha realizado en el marco del proyecto de investigación Filosofía de la Imagen (FFI2011-26621), financiado por el Ministerio de Economía, Industria y Competitividad (MINECOEspaña) (Programa Nacional de Proyectos de Investigación Fundamental).

** Doctora en Bellas Artes. Profesora Departamento de Pintura y Conservación-Restauración. Facultad de Bellas Artes. Universidad Complutense de Madrid. Madrid. España. Correo electrónico: rutmartin@pdi.ucm.es.
} 
a series of common strategies in contemporary artivism, thus allowing us to map out the changes in their form and modes of action.

KeYwords: Artivism, images, political art, artistic strategies, mass media.

Recibido: 11.04.18. Aceptado: 13.03.19

\section{INTRODUCCIÓN Y ESTADO DE LA CUESTIÓN}

Ne en año 1970, el artista Cildo Meirelles realiza una serie de obras bajo
el título "Inserciones en circuitos ideológicos". En la primera de esta serie, "Proyecto coca-cola", Meirelles imprime en algunas botellas de cocacola la frase "Yankees go home" y posteriormente las vuelve a poner en circulación. Bajo esta propuesta, el objeto, símbolo inequívoco del imperialismo norteamericano, se convierte en punto de partida para establecer un cuestionamiento político. Por otra parte, funciona como un catalizador para hacer circular mensajes particulares de índole política, fomentando unos canales de comunicación no oficiales insertados en lo cotidiano. La creación de un circuito de información alternativo, participativo, horizontal que, además, se sirve del propio sistema de circulación capitalista que se pretende cuestionar es, sin duda, uno de los máximos intereses de la estrategia puesta en marcha por Meirelles. Esta serie de obras nos propone, por un lado, un punto de partida, las décadas de los años 60 y 70 del siglo pasado en las que se asientan los modus operandi que nos llevan hasta hoy. Nos proponen, así mismo, otro aspecto clave que, como veremos, va a caracterizar muchas de las propuestas actuales, y es precisamente, su capacidad de infiltrarse en el sistema para transformarlo desde dentro, ya que la "transformación social no ocurre simplemente por una concentración masiva a favor de una causa, sino precisamente a través de las formas en que las relaciones sociales cotidianas son rearticuladas y nuevos horizontes conceptuales abiertos por prácticas anómalas y subversivas" (Butler, Laclau, Žižek, 2004, p.20).

\subsection{Contexto de inserción. Imágenes híbridas: entre lo (post)mediático yel arte}

Dentro del flujo continuo de imágenes en el que nos situamos en la actualidad, provenientes de los más variados dispositivos pantalla, nos encontramos con la imagen convertida en un dispositivo informacional y 
significativo con una fuerza sin precedentes. Dichas imágenes no plantean únicamente cómo es una sociedad, sino que construyen sus imaginarios (Hernández, Fernández, Baptista, 2006). Este panorama se ve ampliado en los últimos años a lo que Rehder y Hentschel (2016) han denominado "Outernet", entendido como la expansión de internet fuera del entorno online.

Desde este punto de vista se entiende cómo las imágenes que permiten crear otros imaginarios posibles o, como diría Rancière (2008b), que "contribuyen a dibujar un nuevo paisaje de lo visible, lo decible y lo posible" pueden funcionar como aperturas significativas, en ese continuo icónico y su relación implícita con los intereses del poder. Tal y como expone Mitchell (2009), en la actualidad se ha dado "un redescubrimiento post-lingüístico de la imagen como un complejo juego entre la visualidad, los aparatos, las instituciones, los discursos, los cuerpos y la figurabilidad" (p. 23). Las imágenes que se sirven de lo artístico y se insertan en lo mediático y en lo público pueden servir, precisamente, para articular nuevas lógicas significativas desde unas formas de ver conocidas e interiorizadas por todos.

La imagen como dispositivo comunicacional, lejos de tener un papel ilustrativo dentro de los medios de comunicación y las redes sociales, se ha convertido en el eje prioritario de significación en un entorno mediático en el que prima la inmediatez y el flujo continuo de información, eminentemente visual. "La promiscuidad y la ubicuidad de las imágenes, la contaminación viral de las cosas por imágenes, son características de nuestra cultura" (Baudrillard, 2001, p. 31). Podría decirse que en las imágenes artísticas lo representacional cede camino a la interpretación y la conjugación de esta con las distintas subjetividades, capaces de abrir posibles imaginarios alternativos.

Con la multiplicación de las redes de comunicación, no se han incrementado únicamente las imágenes que continuamente vemos y compartimos, sino que también se han multiplicado de forma significativa los emisores de dichas imágenes. Lo anterior, al menos en teoría, debería suponer la multiplicación de discursos o la mayor diversidad en los relatos que conforman el denso imaginario icónico con el que convivimos. Sin duda, esto ha interferido en sus formas, que cada vez diluyen más los límites entre las imágenes de la cotidianeidad y las imágenes de los medios. Aun así, el creciente interés por las miradas particulares, heredado por el auge posmoderno de las micronarrativas ligadas a la visibilización de las minorías, ha acabado siendo absorbido por ese discurso unificador en su significado y puesto a merced de los intereses de los sistemas de poder. Si en las décadas 
de los 80 y 90 la visibilización y la reivindicación de otras culturas dio como resultado unas imágenes subversivas, estas hoy día han sido asumidas hasta el punto de disfrazar la mirada homogeneizante del sistema en una multiplicidad de miradas que lo es únicamente en apariencia y que, eso sí, ha incrementado su capacidad de difusión de forma exponencial y por tanto, su fuerza como transmisor de un imaginario determinado. Un imaginario, además, fácil de asumir y de comprender, a través de formas heredadas y ligadas de un modo concreto a la representación de lo real, "la particular mirada que cada época histórica construye, consagra un régimen escópico o sea, un particular comportamiento de la percepción visual" (Jay, 2003, p. 221). Hemos pasado de una imagen dependiente del medio que la transmitía, y que por ello se sujetaba a un significado y lectura específica, a un flujo de imágenes inestables y ambiguas.

Otra de las cuestiones a tener en cuenta es que, hoy día, nuestra manera de percibir las imágenes es cada vez más inmediata, determinadas por la velocidad y multiplicidad de su flujo, pero también de una mirada que se ha acostumbrado a ser cada vez menos reflexiva o menos consciente. Imágenes cada vez más efímeras y sin permanencia. Esto tiene dos consecuencias importantes, por un lado, impone unas estrategias artísticas que funcionen de manera inmediata en la imagen, es decir, que sean capaces de llamar la atención en un primer acercamiento a la misma. Por otro, la necesidad de plantear imágenes de crítica que permitan una reflexión a posteriori y que no impliquen un tiempo de contemplación.

Podría decirse que la imagen artística es capaz de crear réplica, es decir, no se agota en su significado totalizador, sino que permite al otro intervenir en su significación ampliando así sus ámbitos de sentido. Esta característica es básica para deconstruir esos relatos de los sistemas del poder y permitir la inserción de contradiscursos. Unos contradiscursos que, por ende, se entienden permeables, abiertos a las distintas subjetividades y en continua transformación. "La emergencia de estas nuevas prácticas de subjetivación en una era posmedia será posible, sobre todo, por la reapropiación concertada de las tecnologías de la información y la comunicación" (Guattari, 2013, p. 42). Es quizás aquí donde lo artístico tome relevancia como dispositivo para la acción política, precisamente en esa capacidad de que los campos abiertos a sentidos no unidireccionales permitan una implicación a favor de una causa, una transformación en el seno de lo social y una creación colectiva de espacio político.

La capacidad performativa de la imagen desde el punto de vista ideoló- 
gico está fuera de toda duda. En línea con lo planteado por Lucy R. Lippard (1984), se acepta que todo arte es ideológico y que todo arte es usado políticamente, consciente o inconscientemente. Las cuestiones que se formulan entonces son: ¿qué ocurre cuando se crean unas imágenes capaces de ir contra ese discurso dominante?, ¿cómo deben ser estas imágenes que nadan a contracorriente para tener realmente una fuerza transformadora?, ¿desde qué estrategias y/o tácticas se desarrollan?, ¿cuáles son las intersecciones que se producen en estos procesos? En base a estas cuestiones se plantea, por tanto, cuáles son los modos de hacer de esas imágenes, que se ponen en marcha desde procesos artísticos y se infiltran en los medios de la cultura visual contemporánea. Se van a analizar las estrategias artísticas de este tipo de imágenes, que han tenido un recorrido histórico a partir de los años 60 del siglo pasado y que han llegado a los movimientos sociales y activistas de principios del siglo XXI.

\section{TOMA DE CONCIENCIA. LOS POTENCIALES Y LOS DESAFÍOS DE LA IMAGEN EN EL ARTIVISMO ${ }^{1}$}

En la imagen artística se reivindica como elemento de significación la parte emocional del sujeto, aquella que contempla la experiencia y los afectos como puntos claves en su significado. Cabe decir que, cada vez más, estos modos de proceder en la imagen artística están siendo incorporados a ese flujo icónico impuesto que encuentra en lo experiencial otro disfraz, para implicar al individuo en su discurso en virtud de una identidad preformada, cuestionando en este punto no solamente la objetividad de la imagen, sino indagando en terrenos que eran propios de lo artístico, como era la subjetividad. La imagen artística trabaja, además, en varios tiempos, a través de una capacidad de contemplación heredada de las formas de mirar el arte a lo largo de la historia, pero también a través de un tiempo que supera la imagen, es decir, un tiempo de pervivencia de la imagen que sobrevive a la mirada de la misma. Su complejidad y su apertura semántica son claves

\footnotetext{
${ }^{1}$ Artivismo (artivism) hace mención a la unión de los términos arte y activismo. Este término comienza a utilizarse en el marco de las protestas antiglobalización y los conflictos bélicos que se sitúan a comienzos del siglo XX, en la primera década de los años 2000. Para más información puede consultarse Jordan (2016).
} 
en estos procesos. Tal y como apunta Boehm (2011), "las imágenes son en cierto modo fijaciones que permiten congelar lo vivo en la materia y volver a revivirlo por medios artísticos" (p. 102).

Las estrategias artísticas puestas en marcha desde el campo del artivismo son múltiples, aunque cabe destacar que tienen una naturaleza híbrida que permite interferir en el relato dominante a través de varios flancos, provenientes de apropiaciones y relecturas de modos de hacer propios de los medios de comunicación y de las tácticas políticas normativas y de las experiencias en la cotidianeidad. "Las imágenes constituyen un punto singular de fricción y desasosiego que atraviesa transversalmente una gran variedad de campos de investigación" (Mitchell, 2009, p. 21). Destaca también su capacidad transformadora, es decir, el objetivo de estas imágenes está puesto al servicio del movimiento social y activista que le da cabida. Sus fines, por lo tanto, persiguen el cambio social y esto es lo que determina sus estrategias, sus procesos y sus formas. Estas imágenes no pueden ser entendidas bajo los paradigmas formalistas del arte, aquellos que abordan cuestiones estéticas heredadas de la modernidad, sino que quedan legitimadas en la medida en que son más efectivas desde ese punto performativo expuesto.

Sus modos de intervención son procesuales y su poder de actuación podría establecerse a mediano-largo plazo. En este sentido, se podría aludir a una cadena de procesos encadenados que suceden tras su puesta en marcha. En primer lugar, es necesario abordar los procesos que se ponen en marcha sobre el territorio, es decir, antes de su materialización como imagen, el impacto de las intervenciones en el marco de los movimientos sociales o las actuaciones activistas concretas. En segundo lugar, los procesos que se inician una vez que la intervención ha concluido, pero la imagen comienza a extenderse por los circuitos ideológicos, bien sean los medios de comunicación, tecnologías digitales o las redes sociales. En tercer lugar, podría hacerse mención a los procesos de cambio iconográfico que se producen una vez infiltradas y, por último, a su capacidad de actuar como catalizadores de otros procesos similares en la arena política y en la cultura visual. 


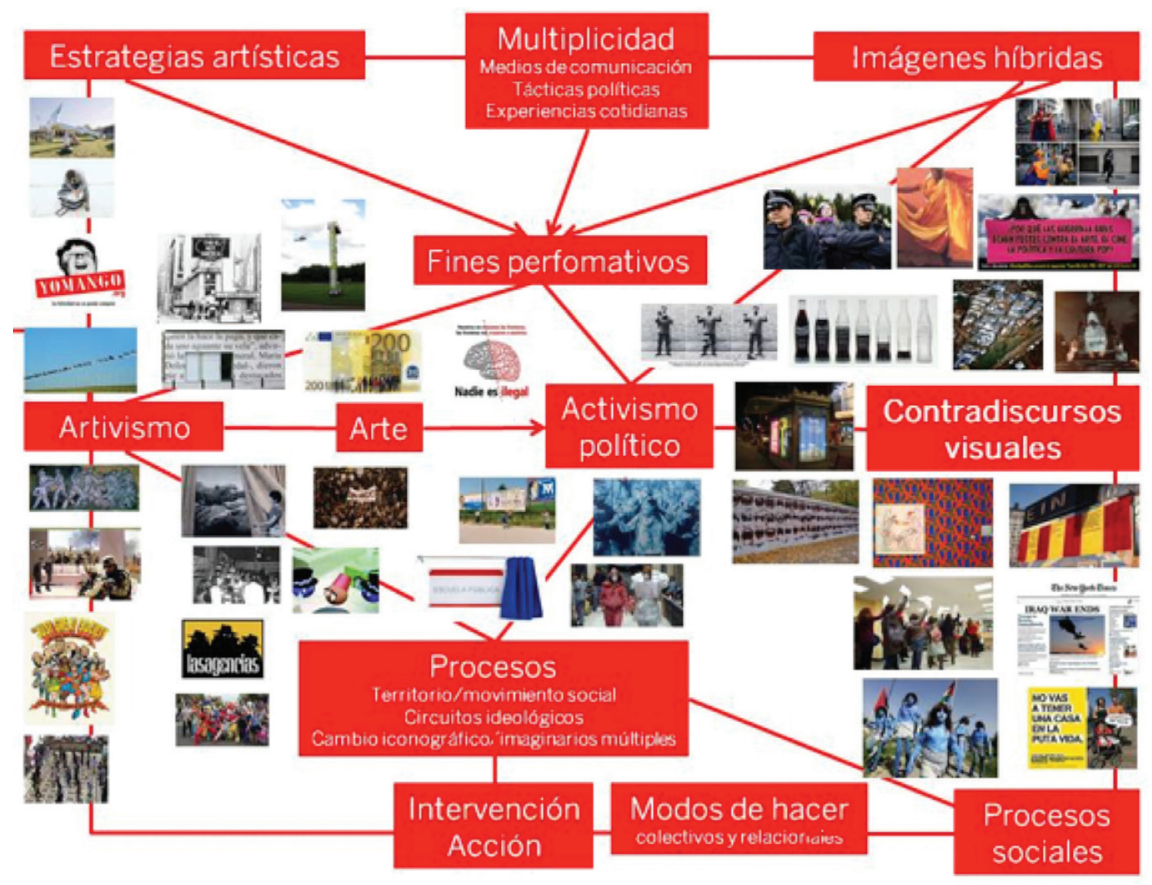

Tabla 1. Mapa conceptual/visual del análisis relacional de las prácticas objeto de estudio.

El espacio privilegiado de actuación de estas imágenes es la esfera pública. Sirva como ejemplo la obra de Meirelles. El poder performativo de la misma se ve desactivado en el momento en el que es acotado a los espacios de difusión propios de lo artístico, es decir, a las instituciones culturales. El objetivo político de la obra es anulado. Esa obra ya no puede ser vista ni desde una lectura política, ni desde una lectura estética. Sirva, de nuevo, este ejemplo para valorar el resto de propuestas que se plantean y para entender cómo la estrategia que pone en marcha estas imágenes es la de crear espacio político. Para Alexander Kluge y Oskar Negt (2001), la esfera pública (Habermas, 2000) sería el lugar donde se enmarca la experiencia, oponiendo este espacio al espacio privado y aludiendo a su subjetividad. Es, además, para estos autores un espacio constituido por experiencias comunicables, comprensibles por la comunidad. En este sentido, podría decirse que estas imágenes que se cuelan entre los intersticios del sistema 
dominante, serían capaces de generar un espacio político alternativo al que generan otros medios de la industria cultural.

De acuerdo con lo que afirma Critical Art Ensemble (CAE) (1993) el desarrollo de las tecnologías informáticas ha reconfigurado radicalmente los sistemas de poder, transformando, por lo tanto, lo que entendemos por resistencia. La localización de dicho poder está caracterizada en la actualidad por su carácter ambiguo, que no entiende de límites o fronteras y que hace unas décadas era inimaginable.

Los desafíos de estas imágenes no son pocos. De ahí la evolución de las estrategias que las ponen en marcha a lo largo de estas últimas décadas. $\mathrm{Si}$ se citaba anteriormente cómo el contexto de actuación de las mismas define en gran medida sus modos y sus formas, se considera, por tanto, que los nuevos requerimientos de las luchas políticas actuales hayan modificado sus estrategias en pro de su capacidad de articular determinados discursos unidos a las luchas políticas. Estas problemáticas se han ido solucionando creativamente de las más diversas formas, pero es interesante señalar varias cuestiones de carácter general que han supuesto un desafío importante a lo largo de todo este tiempo. Por un lado, ese vínculo entre lo artístico y lo político que ha llevado a discutir activamente sobre la estetización de la política o la politización de la estética. Rancière (2008a) plantea que " [u] $\mathrm{n}$ arte crítico es un arte que sabe que su efecto político pasa por la distancia estética. Sabe que este efecto no puede garantizarse, que conlleva siempre una parte de indeterminación". Por otro lado, nos encontramos con la capacidad de fagocitación del sistema hegemónico de cualquier práctica subversiva que lo cuestione (Foster, 2001). En parte, por estas cuestiones se puede decir que este tipo de prácticas artísticas está continuamente reinventándose, forzando los límites para comprobar cómo y hasta dónde puede llegar su flexibilidad. Son imágenes desacomodadas que pretenden seguir siéndolo.

\section{ESTRATEGIAS ARTÍSTICAS PARA LA CREACIÓN DE ARTEFACTOS VISUALES DE ACCIÓN POLÍTICA}

Ante esta situación se ha comprobado que existe una serie de estrategias que permiten ampliar el campo de sentido de las imágenes mediáticas, en la medida en que fuerzan unas disrupciones que potencian la reflexión y la interpretación más allá del discurso dominante. Se ha evaluado, así mismo, cómo dicha tensión puede devenir en capacidad de transformación en base a los postulados del artivismo. 


\subsection{Estrategias de apropiación de imágenes mediáticas y su conversión en imágenes artísticas}

Una de las estrategias más utilizadas, conocidas y asimiladas al día de hoy, para cuestionar el discurso de los sistemas de poder, que además ha tenido un largo recorrido desde las manifestaciones de arte político de la década de los 70 del siglo XX, ha sido la apropiación de imágenes de prensa, mediáticas y publicitarias para, a través de estos elementos conocidos por todos, forzar nuevos significados a partir de la relación de sus elementos de origen diverso y su contextualización en diversos ámbitos. Martha Rosler es una de las artistas que, durante la década de los 70, exploró y puso en marcha esta estrategia en muchas de sus obras. Dichas obras suponen un punto de partida de una estrategia que ha venido utilizándose de forma significativa hasta nuestros días.

Esta estrategia plantea dos cuestiones fundamentales. Por un lado, la contraposición de imágenes de diversas fuentes que, en muchas ocasiones, también generan un fuerte contraste en los temas de sus representaciones. La mirada se cruza entonces con un imaginario conocido que se presenta de otra manera, causando a la vez una identificación (las imágenes son conocidas, cotidianas y susceptibles de ser releídas a través de experiencias particulares) y una extrañeza inicial (el citado contraste). Esto implica la articulación de otros discursos. La imagen, además, interroga al espectador al plantear problemas no resueltos en su representación formal. Es decir, busca su respuesta, y es, precisamente, este carácter conversacional uno de los aspectos que diferencian las imágenes artivísticas del resto de imágenes.

\subsection{Cambio de escenario. Asalto a los canales mediáticos en la esfera pública}

Muchos artistas conscientes de las repercusiones y condicionamientos de los mensajes políticos y su poco poder de transformación al ser recluidos en las instituciones culturales plantean la estrategia de asaltar los canales mediáticos de difusión de las mismas en el espacio público. "De manera subjetiva, el territorio de la calle es la liberación de la privacidad impuesta, es un espacio de posibilidades, una apertura de deseo social" (Holmes, 2016). Esta estrategia, utilizada masivamente en los movimientos de visibilización de minorías y de la crítica a la representación acontecidos en las dos décadas finales del siglo pasado, ha demostrado tener un gran impacto social y ha puesto de manifiesto lo importante que es la inserción de estas imágenes en los espacios cotidianos, a fin de multiplicar exponencialmente las pequeñas o grandes transformaciones que de ellas puedan surgir. 
En este caso, surge un proceso de extrañeza similar al planteado en torno a la apropiación de las imágenes mediáticas. El espectador acostumbrado a leer los mensajes en estas plataformas de una manera determinada se ve increpado y se ve forzado a cambiar el sentido. La imagen infiltrada en estas plataformas parte del hecho de que el condicionamiento del soporte imprime a la mirada un carácter de inmediatez. Este fenómeno puede observarse de forma clara en las obras de Alfredo Jarr, en las que a través de carteles de factura publicitaria interroga al ciudadano sobre la responsabilidad de los medios y la cultura en las guerras del mundo. Se utiliza, así mismo, de forma ejemplar en la propuesta de Rogelio López Cuenca para la Bienal de Arte, Arquitectura y Paisaje (2005). En este caso, el artista se apropia de todos los elementos formales de la campaña institucional "El total es lo que cuenta" para cuestionar proyectos producidos por instituciones públicas que, en su opinión, representan ejemplos de despilfarro a gran escala.

Es por eso por lo que en sus formas estas imágenes son pretendidamente simples, de comprensión inmediata e imitan las formas de las imágenes publicitarias. Imágenes travestidas que encuentran su impacto en los contundentes mensajes que propugnan, que no dejan indiferentes y que pretenden implicar directamente a la acción colectiva a favor de una causa. Cuando el colectivo Todo por la Praxis (2011) plantea generar una intervención en la Cañada Real ${ }^{2}$ que se apropie de una iconografía conocida por todos (Hollywood Sign), está posibilitando dos tipos de cuestiones básicas. En primer lugar, visibiliza el territorio y sus problemáticas asociadas, empodera a los vecinos y vecinas del barrio y, en segundo lugar, genera un espacio susceptible de ser convertido en imagen mediática que sustituya las imágenes que habitualmente aparecen en los medios al tratar de la Cañada Real y que han ayudado a construir un imaginario particular altamente peyorativo.

La utilización del texto conviviendo con lo icónico es otra de sus características y esta elección permite no beneficiarse de lo referencial de la imagen publicitaria, sino también llegar de manera muy directa al mensaje. La estrategia planteada por Democracia (2009), en su obra "Subtextos"3 consiste en insertar mensajes escritos en árabe en los espacios dedicados a la publicidad en el espacio público. "Estos mensajes servirán para visibilizar la heterogeneidad propia de la sociedad civil (...) el resto de la ciudadanía

\footnotetext{
${ }^{2}$ Para más información sobre esta obra puede consultarse: https://todoporlapraxis.es/024_plancanada_descargables/

${ }^{3}$ Puede consultarse más información sobre esta intervención en http://www.democracia.com.es/ proyectos/subtextos/
} 
tendrá presente la existencia de este grupo en el seno de la vida social con sus particularidades culturales" (Democracia, 2009).

\subsection{Estrategias lúdico-festivas y estrategias de escenificación en la arena política}

En el siglo XXI, las propuestas de carácter artivista tienen mucha relación con protestas multitudinarias a los sistemas de poder de una sociedad que, en general, va perdiendo posición en una crisis global. Los proyectos colectivos parten de estrategias artísticas para el vínculo social, que beben de fuentes comunes como el consumo, la guerrilla de comunicación, formas de movilización y protesta con bases creativas, propuestas en las que a través de la ironía, lo lúdico y el humor se establece una crítica que trata de romper y cambiar los discursos normativos, dando lugar a nuevos imaginarios capaces de generar comunidad, nexos de unión no preconcebidos. Hoy día los vínculos identitarios son mucho menos fuertes que décadas atrás, lo que resta solidez a esas uniones colectivas, más fugaces, más efímeras y más débiles. De ahí que parte de las estrategias que se ponen en marcha actualmente sea precisamente la de incidir en esos lazos colectivos, en la relación entre los distintos agentes implicados para acrecentar la fuerza de los movimientos y con esto su capacidad performativa.

Es por esto por lo que hoy se conciben una serie de estrategias múltiples, más dinámicas y flexibles que se despliegan para lograr varios objetivos. Se podrían destacar dos que trabajan simultáneamente. En primer lugar, destacan las estrategias de escenificación y construcción de situaciones. Esto supone una concepción de la esfera pública como un escenario, en el que se crea una composición orquestada de intervenciones visuales que se convertirán en imagen mediática. En segundo lugar, son significativas las estrategias lúdico-festivas puestas al servicio de lo relacional, es decir, al objetivo de promover la experiencia como acción colectiva para el cambio.

El principal objetivo que persigue la primera de las estrategias citadas es romper la imagen preconcebida y servir de estímulos visuales para una relectura en base a otros discursos no dominantes. "Un arte crítico tiene menos de un arte que revela las formas del poder que de un arte que modifica las líneas divisorias existentes entre los regímenes de representación sensibles" (Rancière, 2008b).

En el desarrollo de estas prácticas se parte del estudio de una iconografía específica ligada a la representación que la cultura visual hace de un determinado tema o contexto y, a partir del mismo, se investiga cómo 
la intervención en la acción o la construcción de la situación puede fisurar esa iconografía, férreamente construida en el inconsciente colectivo. La intervención visual es prioritaria, de tal modo que permite convertir la imagen mediática que surgirá de la misma en una contraimagen y, consecuentemente, en un contradiscurso. Baudrillard (2007) expone "el papel de la imagen es notablemente ambiguo. Al mismo tiempo que exalta el acontecimiento lo toma como rehén (...). En tanto que acontecimiento-imagen, le otorga un impacto hasta ahora inédito". Esto conecta con las acciones de FLO6x8, "Flashmob Rumba Rave Banquero"4 (2010), una acción que tenía como objetivo crear una acción artivista en la que se ocupara temporalmente una sucursal bancaria para el desarrollo de una flashmob con una crítica explícita al sistema financiero capitalista. En el mismo sentido pueden entenderse las acciones realizadas por el colectivo Yomango o la acción "Registro"5 de Yolanda Domínguez (2014).

El impacto de estas acciones sirve de motor de difusión, así como su carácter viral, ya que los canales mediáticos y los recursos de las redes sociales permiten un impacto impensable en los movimientos sociales, protestas y acciones de décadas pasadas. La idea de que la imagen rompa con el discurso único se ve incrementada en la medida en que es mayor el número de personas que tienen acceso a la misma.

Para evitar que tal y como plantea Baudrillard (2007) el acontecimiento desaparezca tras su puesta en imagen -"La imagen consume el evento, en el que se absorbe y se lo da a consumir"-, se incide en la introducción de estrategias lúdico-festivas que potencian lo experiencial vinculado a los afectos, las emociones, la diversidad de subjetividades y la diversión. Laura Baigorri (2003) expone que el paso definitivo se da desde la simulación a la suplantación, en el que la "nueva versión de los hechos reemplaza y desbanca a la anterior". Unas experiencias que además tienen lugar en colectividad y que, por lo tanto, generan vínculos de acción comunitaria. "Podemos entonces caracterizar cómo la festividad amenazadora, el desordenamiento carnavalesco o la confrontación lúdica reverberan globalmente en las nuevas herramientas de lucha" (Expósito, 2014, p. 225). Si como expone Brian Holmes (2016) un evento es una ruptura en un flujo normalizado de

\footnotetext{
${ }^{4}$ El vídeo de la acción puede consultarse en https://www.youtube.com/watch?v=71QPDXyrv98

${ }^{5}$ Puede consultarse más información en la siguiente dirección web: https://yolandadominguez. com/portfolio/registro/
} 
experiencias, se entiende cómo, cuando esto ocurre en colectividad, puede llegar a provocar acción y debate político. Es importante constatar que este objetivo de generar vínculos colectivos que den fuerza a los reclamos de los movimientos sociales no es algo que esté subordinado a la imagen, no es un objetivo secundario de las manifestaciones artivistas, sino que transitan por caminos paralelos en pos de potenciarse mutuamente. Esta estrategia se puso en marcha en las contracumbres de la primera onda global de movimientos -Seattle 1999, Génova 2001- y su punto de partida está en las Street parties de Reclaim the streets en Gran Bretaña, durante la década de los 90 del siglo XX.

Otras de las constantes dentro de las prácticas artivistas contemporáneas son las técnicas de hacking llevadas al contexto de manifestaciones o protestas. Esto fue utilizado por la agencia Prêt à Revolter, surgida del "De la acción directa considerada como una de las Bellas Artes"' (MACBA, 2000) o por CIRCA (Clandestine Insurgent Rebel Clown Army), muy presente en la visita de Bush al Reino Unido (2003). Algo que también es perceptible en "The Adventures of Unemployed Man"7 (2010), un guion de comic de las aventuras de superhéroes sociales que después abandonan las páginas de los comics para aparecer en las manifestaciones. Estos ejemplos visibilizan unos modos de generar acontecimientos, muy significativos dentro del artivismo, en el seno de la protesta, pero que también producen una imagen mediática que rompe la realidad de consenso, proponiendo la construcción de experiencias e imaginarios alternativos.

El arte se convierte así en un eje transversal y propone unos modos de acción específicos con vinculación directa a las ciencias sociales y las acciones de resistencia. Sirve como ejemplo el colectivo alemán Ecleptic Electric.

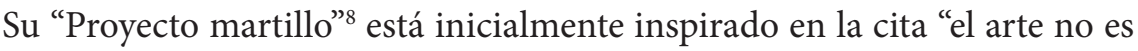
un espejo de la realidad, sino un martillo con el que darle forma" (Ecleptic Electric, 2010), que logró traer a primer plano de los medios de comunicación las protestas activistas surgidas en torno a la Conferencia de las Naciones Unidas sobre Cambio Climático (Cancún, 2010).

\footnotetext{
${ }^{6}$ Puede consultarse el programa de los talleres en https://www.macba.cat/es/de-la-accion-directaconsiderada-como-una-de-las-bellas-artes

${ }^{7}$ Para más información consultar: http://unemployedman.com/\#about

${ }^{8}$ Para más información sobre este proyecto puede consultarse: http://www.minorcompositions. info/wp-content/uploads/2012/01/elmartillo-web.pdf
} 


\section{DISCUSIÓN Y CONCLUSIONES}

En este sentido, es necesaria una lectura de las imágenes que no focalice su carácter estético, los paradigmas han cambiado y tendrían que ver con la idea de Benjamin (2004) de una innovación artística vinculada a una revolución social. En esa posibilidad de desplegarse como imagen a través de sí, la imagen artística no se sirve únicamente de sus modos de hacer históricos, sino que es, también, a través de la apropiación y reconversión de las formas propias de ese universo icónico cotidiano como proceden a intervenir los espacios de poder. Rearticular los elementos dados y escenografiar los escenarios cotidianos para acentuar su carácter mediático y ficcional son algunas de sus estrategias en este aparecer como imagen postmediática y seguir manteniendo su complejidad significativa propia de lo artístico. Este tipo de imágenes entre lo mediático y lo artístico mantiene esa posibilidad continua de no ser lo que parece ser. Se produce, entonces, una tensión entre los modos de ver la imagen. Por un lado, nos lleva a la inmediatez propia del visionado de la imagen mediática, en la que identificamos sus elementos y por lo tanto adoptamos una mirada fugaz. Y, por otro, nos encontramos con una fuerza que nos plantea un desafío y la entrada a otros ámbitos de sentido. Es esa tensión la que fuerza su capacidad transformadora. El hecho artístico se puede abrir, así, a la transformación social, que permite activar ciertos mecanismos que despierten el interés social de implicación. "Arte y política comienzan cuando se perturba el juego cotidiano que hace deslizarse continuamente las palabras bajo las cosas y las cosas bajo las palabras. Comienzan cuando las palabras toman figura, cuando devienen realidades sólidas, visibles" (Rancière, 2008b, p. 83).

Como puede desprenderse de las acciones analizadas, la utilización de estrategias de carácter artístico en el seno de lo político y el activismo, y su influencia en una construcción de imágenes que se traslada al ámbito mediático y comunicacional, potencia de forma significativa la capacidad de transformación social y la reflexión más allá de los sistemas de poder. Las imágenes artivísticas que aluden a su carácter referencial y relacional son capaces de generar un ámbito conversacional en una temporalidad sostenida que permita transitar entre lo ficcional y lo real, lo construido y lo dado, la materia y lo virtual. Imágenes que actúan como dispositivos de mediación con capacidad de incidir en lo social con fuerza transformadora y con capacidad de dar cabida y conformar múltiples subjetividades en la esfera pública. 


\section{REFERENCIAS}

Baigorri, L. (2003). Del artivismo simulatorio a las tácticas de suplantación en la Red. No más arte, sólo vida 2.0. Telos, 56, Segunda Época. Recuperado de: https://telos.fundaciontelefonica.com/telos/articulocuaderno.asp@idar ticulo $=7 \&$ rev $=56 . \mathrm{htm}$

Baudrillard, J. (2001). El otro por sí mismo, 4a ed. Barcelona, España: Editorial Anagrama.

Baudrillard, J. (2007, marzo 6). L'esprit du terrorisme, par Jean Baudrillard. Le Monde. Recuperado de: https://www.lemonde.fr/disparitions/article /2007/03/06/1-esprit-du-terrorisme-par-jean-baudrillard_879920_3382. html

Benjamin, W. (2004). El autor como productor. México: Ítaca.

Boehm, G. (2011). ¿Más allá del lenguaje? Apuntes sobre la lógica de las imágenes. En: García Varas (Ed.). Filosofía de la imagen (pp. 87-106). Salamanca, España: Ediciones Universidad de Salamanca.

Butler, J., Laclau, E. y Žižek, S. (2004). Contingencia, hegemonía, universalidad: diálogos contemporáneos en la izquierda ( $1^{\text {a }}$ ed. en español, $2^{\text {a }}$ reimp.). Buenos Aires, Argentina: Fondo de Cultura Económica.

CIRCA (2003). Clandestine Insurgent Rebel Clow Army (Colectivo artivista). Recuperado de: https://es-es.facebook.com/circaclowns/

Critical Art Ensemble (CAE). (1993). The Electronic Disturbance. Nueva York, EEUU: Autonomedia. Recuperado de: http://www.critical-art.net/books/ ted/

Democracia (2009). Subtextos [Intervención urbana]. Recuperado de: http:// www.democracia.com.es/proyectos/subtextos/

Domínguez, Y. (2014). Registro (Intervención artivista). Recuperado de: https://yolandadominguez.com/portfolio/registro/

Ecleptic Electric (2010). The Martillo Project. Recuperado de: http://www. minorcompositions.info/wp-content/uploads/2012/01/elmartillo-web.pdf

Expósito, M. (2014). Todo mi cuerpo recuerda: desorden festivo, mutación subjetiva y devenir revolucionario. En Playgrounds: reinventar la plaza: [exposición], Museo Nacional Centro de Arte Reina Sofía, 30 de abril - 22 de septiembre de 2014. Madrid, España: MNCARS. Recuperado de: http:// www.museoreinasofia.es/exposiciones/playgrounds

FLO6x8 (2010). Flashmob Rumba Rave Banquero (Intervención artivista). Recuperado de: https://www.youtube.com/watch?v=71QPDXyrv98.

Foster, H. (2001). Remodificaciones: hacia una noción de lo político en el arte contemporáneo. En: Blanco, P. (Ed.) Modos de hacer: arte crítico, esfera pública y acción directa (pp. 95-126). Salamanca, España: Ediciones Universidad de Salamanca.

Guattari, F. (2013). Schizoanalytic Cartographies. London, Reino Unido; New York, EEUU: Bloomsbury Academic.

Habermas, J. (2000). Historia y crítica de la opinión pública: la transformación 
estructural de la vida pública (Vols. 1-1). Barcelona, España: Gustavo Gili. Recuperado de: http://ffyll.uncu.edu.ar/IMG/pdf/Habermas_Historia_y_ critica_de_la_opinion_publica.pdf

Hernández Sampieri, R.; Fernández Collado, C., y Baptista Lucio, P. (2006). Metodología de la investigación (4 $4^{\mathrm{a}}$ ed.). (Vols. 1-1). Mexico, Distrito Federal: McGraw-Hill Interamericana.

Holmes, B. (2016). Activismo/esquizoanálisis. La articulación del discurso político. Re-visiones, 0(3). Recuperado de: http://www.re-visiones.net/ index.php/RE-VISIONES/article/view/78

Jay, M.E. (2003). Regímenes escópicos de la modernidad. Campos de fuerza, entre la historia intelectual y la crítica cultural (pp. 221-252). Buenos Aires, Argentina: Paidós.

Jordan J. (2016). Artivism. Injecting Imagination into Degrowth. Deglowth in Bewgung(en). Recuperado de: https://www.degrowth.info/wp-content/uploads/2016/07/DIM_Artivism.pdf

Kluge, A.; Negt, O. (2001). Esfera pública y experiencia. Hacia un análisis de las esferas pública burguesa y proletaria. En: Blanco, P. (Ed.), Modos de hacer: arte crítico, esfera pública y acción directa (pp. 226-272). Salamanca, España: Ediciones Universidad de Salamanca.

Lippard, L.R. (1984). Art and Ideology. New York, EEUU: New Museum of Contemporary Art. Martín,

López Cuenca, R. (2005). El total es lo que cuenta (Intervención urbana). Bienal de Arte, Arquitectura y Paisaje.

MACBA (2000). Prêt à Revolter. De la acción directa considerada como una de las Bellas Artes. Barcelona, España: MACBA. Recuperado de: https://www. macba.cat/es/de-la-accion-directa-considerada-como-una-de-las-bellasartes

Mitchell, W. J. T. (2009). Teoría de la imagen: ensayos sobre representación verbal y visual. Madrid, España: Akal.

Rancière, J. (2008a). El teatro de las imágenes. En Jaar, A. (Ed). La política de las imágenes ( $1^{\mathrm{a}} \mathrm{ed}$.) (pp. 69-88). Santiago de Chile, Chile: Editorial Metales Pesados.

Rancière, J. (2008b). Estética y política: las paradojas del arte político. Recuperado https://webs.ucm.es/info/artepltk/texto_ranciere.html

Rehder, T., \& René Hentschel, R. (2016). The Outernet. Say Hello to the Wild World Web! Recuperado de: https://www.mediacom.com/uk/article/ index?id=the-outernet-say-hello-to-the-wild-world-web!

The adventures of Unemployed Man (2010). (Comic). Recuperado de: http:// unemployedman.com/

Todo por la Praxis (2011). Cañada Real (Intervención urbana). Recuperado de: http://todoporlapraxis.es/wp-content/uploads/simple-file-list/024_canada_concurso_lamina1.pdf. 